\title{
FIRST RESULTS OF PACTE GROUP'S EXPERIMENTAL RESEARCH ON TRANSLATION COMPETENCE ACQUISITION: THE ACQUISITION OF DECLARATIVE KNOWLEDGE OF TRANSLATION
}

\author{
PACTE Research Group ${ }^{1}$ \\ Universitat Autònoma de Barcelona (Spain) \\ gr.pacte@uab.es
}

\begin{abstract}
This paper presents the first results of empirical-experimental research into the Acquisition of Translation Competence (ATC): the acquisition of declarative knowledge about translation. This study is based on our previous research about Translation Competence (TC). Some of the data collection instruments have, however, been adapted for current use. Details of our research design include type of study, universe and sample population, study variables, data collection instruments, and data analysis processes. The dependent variables were knowledge of translation; translation project; identification and solution of translation problems; decision-making; efficacy of the translation process; and use of instrumental resources.

The results of the first variable analysed ("Knowledge of Translation") will be presented. A questionnaire with 27 items was used to obtain data on translator trainees' knowledge of translation: their concept of translation and TC; translation units; types of translation problems; the different phases involved in the translation process; methods required; procedures used (strategies and techniques); and the role of the translation brief and the target reader. Indicators of this variable were 'dynamic index' and 'coefficient of coherence'. We understand a 'dynamic' concept of translation to
\end{abstract}

1. PACTE members, in alphabetical order: A. Beeby, L. Castillo, O. Fox, A. Galán-Mañas, A. Hurtado Albir, A. Kuznik (Uniwersytet Wroclawski), G. Massana, W. Neunzig, Ch. Olalla, P. Rodríguez-Inés, L. Romero, M. Taffarel \& S. Wimmer. Principal Researcher: A. Hurtado Albir. 
be textual, interpretative, communicative and functional; as opposed to a 'static' concept that may be defined as linguistic and literal. The dynamic index allows us to see whether a subject's implicit knowledge about how translation works is more dynamic or more static, whereas the coherence coefficient allows us to see whether the subject's vision of different aspects of translation is coherent.

\section{Resumen}

Este trabajo presenta los primeros resultados de una investigación empírico-experimental sobre la Adquisición de la Competencia Traductora (ACT): la adquisición de conocimientos declarativos sobre la traducción. Este estudio se basa en nuestra investigación anterior sobre Competencia Traductora (CT), si bien, algunos instrumentos de recogida de datos sobre CT se adaptaron para investigar la ACT. La información sobre el diseño de la investigación incluye tipo de estudio, universo y muestra, variables de estudio, instrumentos para la recogida de datos y proceso de análisis de datos. Las variables dependientes son conocimientos de traducción, proyecto traductor, identificación y resolución de problemas de traducción, toma de decisiones, eficacia del proceso de traducción, y uso de recursos instrumentales.

Aquí se presentan los resultados de la primera variable analizada ("Conocimientos de traducción"). Se usó un cuestionario de 27 ítems para obtener datos sobre los conocimientos de los estudiantes en torno a: concepción de traducción y de la CT, unidad de traducción, tipo de problemas de traducción, etapas que intervienen al traducir, métodos requeridos, procedimientos utilizados (estrategias y técnicas), función del encargo de traducción y del destinatario. Los indicadores de esta variable son: "Índice de dinamismo" y "Coeficiente de coherencia". Diferenciamos entre una concepción "dinámica" de la traducción (textual, interpretativa, comunicativa y funcional) y una concepción "estática" (lingüística y literal). El Índice de dinamismo nos permite determinar si los conocimientos implícitos de los sujetos sobre el funcionamiento de la traducción son más dinámicos o más estáticos, mientras que el Coeficiente de coherencia nos permite saber si la visión de los sujetos sobre diferentes aspectos de la traducción es coherente.

Keywords: Translation. Competence. Acquisition. Knowledge of translation. Declarative knowledge.

Palabras clave: Traducción. Competencia. Adquisición. Conocimientos de traducción. Conocimientos declarativos.

Manuscript received on April 8, 2013 and accepted on November 9, 2013. 


\section{Introduction and research objectives}

This paper presents the first results of PACTE Group's empirical-experimental research into the Acquisition of Translation Competence. The results presented here deal with the acquisition of declarative knowledge about translation, the dependent variable 'knowledge of translation' that was studied earlier in PACTE's Translation Competence experiment. This variable is related to the 'knowledge-of-translation' sub-competence, i.e., the subject's implicit knowledge about the principles of translation. We want to investigate how students' concepts of translation evolve during the process of translation competence acquisition. We grouped these concepts into two main blocks: dynamic concepts (textual, interpretative, communicative, and functional) and static concepts (linguistic and literal).

The overall goal of our research is to study the Acquisition of Translation Competence. In order to reach this goal, we broke the work into two stages: (1) Translation Competence (TC) and (2) the Acquisition of Translation Competence (ATC). The ATC studies include a pilot test (June 2011) and the experiment proper (November 2011). Our ATC research uses the same TC model, variables, indicators and instruments validated in our TC research, although some instruments have been adapted. Thus, some information about this previous research is needed in order to contextualise the ATC results and to allow us to concentrate on our latest results. Therefore, we will begin with a brief summary of the salient aspects of our TC research. More information can be found in PACTE's publications (e.g., PACTE 2008, 2009, 2011a, 2011b.) $)^{2}$

\section{Research into Translation Competence}

\subsection{Definitions and theoretical model}

PACTE defines TC as the underlying system of knowledge, skills and attitudes required to translate. We believe that TC: (a) is expert knowledge; (b)

2. See <http://grupsderecerca.uab.cat/pacte/en/content/publications> 
is predominantly procedural knowledge, i.e., non-declarative; (c) comprises different inter-related sub-competences; and (d), includes a particularly important strategic component. In our model (PACTE 2003), TC comprises five sub-competences (bilingual, extra-linguistic, knowledge of translation, instrumental and strategic) as well as psycho-physiological components. Like all expert knowledge, TC is applicable to problem solving. Solving translation problems involves different cognitive operations within the translation process and requires constant decision-making on the part of the translator. ${ }^{3}$ Expert translators thus possess the ability to solve problems, which forms part of TC. Since all bilinguals possess knowledge of two languages and may also possess extra-linguistic knowledge, we consider the sub-competences specific to TC to be strategic competence, instrumental competence and knowledge of translation. Our research, therefore, focuses on these three competences. We believe the strategic sub-competence to be the most important of all of them, with which it interacts during the translation process, since it serves to make decisions and to solve problems.

\subsection{Research design ${ }^{4}$}

\subsubsection{General hypothesis}

Our general hypothesis is that the degree of TC is reflected in both the process and the product of translating. Our empirical and operational hypotheses are based on PACTE's (2003) TC model.

\subsubsection{Variables and indicators}

One independent variable and five dependent variables were selected for the TC project and have been maintained for the ATC project. The independent variable was the degree of expertise in translation. As there are no external criteria or standardised tests to establish expertise in translation, we started from the premise that translators with a certain amount of professional experience are more expert than those without it. The independent variable has been manipulated accordingly, in terms of a higher or lower degree of experience. Thus, it is a bimodal variable with two categories: more professional

3. Krings (1986) reports that, when analysing translation processes, problems may be detected through the subjects' behaviour: pauses, use of strategies, omissions, corrections, etc.

4. For background information about the conceptual framework used for the research design, see Neunzig (2011). 
translation experience (translators with guaranteed professional experience); less professional translation experience (other foreign language specialists with no professional translation experience).

The dependent variables are: (1) 'knowledge of translation'; (2) 'translation project'; (3) 'identification and solution of translation problems'; (4) 'decision-making'; (5) 'efficacy of the translation process'; and (6) 'use of instrumental resources'. Based on data from our exploratory and pilot tests, a total of 18 indicators related to the six dependent variables were analysed in the TC and ATC studies. Two more indicators have been added, the (transversal) acceptability indicator and the dynamic translation index, related to the 'knowledge of translation' and 'translation project' variables. Thus, a total of 20 indicators have been analysed.

\subsubsection{Universe and sample}

The universe for our TC sample was that of professionals working with foreign languages. From this universe, two experimental groups were selected: professional translators, and foreign-language teachers. Thirty-five professional translators $(\mathrm{N}=35)$ and twenty-four foreign-language teachers $(\mathrm{N}=24)$ participated in the experiment on TC.

\subsubsection{Tasks, instruments and types of analysis}

Subjects performed the following tasks: (1) direct translation; (2) completion of a questionnaire about problems found in the translation; (3) inverse translation; (4) completion of a questionnaire about problems found in the translation; (5) completion of a questionnaire about translation knowledge; (6) participation in a retrospective interview. Hence, data-collection instruments included source texts and translations, questionnaires, and interviews. Further data were obtained by monitoring the translation process with Proxy, making real-time recordings of subjects' actions with Camtasia, and direct observation. ${ }^{5}$ Data were then triangulated by (a) comparing results for the indicators of study variables; (b) comparing translators' and teachers' performance; (c) comparing their performance in direct and inverse translation; (d) comparing results for indicators of all variables and for 'acceptability'.

5. Proxy was a Windows-compatible program to remotely control computers and terminals connected to a network. Camtasia records the subject's actions on the computer in real time and stores these recordings for later study (see <http://www.techsmith.com/ camtasia.html>). 


\subsubsection{Prototypical translation problems: 'Rich points'}

We view translation as a problem-solving process, so we focused on data collection and acceptability analysis of specific source-text segments that contained translation problems. Inspired by Nord (1991), we decided to refer to these segments as rich points. Focusing data collection on selected rich points also aimed to facilitate the collection process, following Giegler's (1994) concept of 'scientific economy,' and triangulation of data (cf. PACTE 2008, 2009; Neunzig 2011).

The rich points were selected as a result of exploratory studies and pilot tests carried out before the experiment (PACTE 2002, 2005a, 2005b). In order to identify rich points in each text, the following types of translation problems were taken into account:

- Linguistic problems: lexical (non-specialised) and morphosyntactic

- Textual problems: coherence, cohesion, text type and genre, and style

- Extralinguistic problems: cultural, encyclopaedic and subject-domain knowledge

- Problems of intentionality: difficulty in understanding information in the source text (speech acts, presuppositions, implicature, intertextual references)

- Problems relating to the translation brief and/or the target-text reader (affecting reformulation) that, from a functionalist point of view, would affect all Rich Points.

The experimental source texts (a Spanish source text for translation into English, French, or German; and English, French and German source texts for translation into Spanish or Catalan), together with five rich points in each of them, were trialled in a 2004 pilot study (reported in PACTE 2005a, 2005b).

\subsubsection{Acceptability as a transversal indicator}

Acceptability is defined in terms of whether or not the solution effectively communicates (a) the meaning of the source text; (b) the function of the translation (within the context of the translation brief, the readers' expectations, and genre conventions in the target culture); and (c) makes use of appropriate language. Thus, 'acceptability' is associated to the quality of the translation product, and these criteria have been used to identify acceptable, semi-acceptable and not acceptable solutions for the rich points selected in the texts. The quantitative and qualitative analysis of data from our exploratory tests (PACTE 2002) and pilot study (PACTE 2005a, 2005b) confirmed 
the importance of this indicator in measuring the subjects' TC. It is the only indicator used in conjunction with specific indicators of each variable.

Results from the TC experiment (PACTE 2008, 2009) showed that the group of translators obtained more acceptable results in their translations than the group of foreign-language teachers, both in direct and inverse translation. However, the difference in the acceptability of the results between both groups is much greater in direct translation (see table 1).

\begin{tabular}{|c|c|c|c|}
\hline \multicolumn{2}{|c|}{ 'Acceptability' } & Translators & Teachers \\
\hline Direct & Mean & 0.73 & 0.49 \\
translation & Median & 0.80 & 0.45 \\
\hline Inverse & Mean & 0.52 & 0.48 \\
translation & Median & 0.50 & 0.40 \\
\hline
\end{tabular}

Table 1. Acceptability scores for direct and inverse translation.

\subsection{Results. Validation of texts and sample}

Results for the variables in the TC experiment can be found in PACTE (2008, $2009,2011 \mathrm{a}, 201 \mathrm{lb}$, and in progress). Here we will just mention some methodological results that validate the experimental design in relation to the selection of texts and subjects. As explained above, acceptability is evaluated in relation to selected rich points in the texts. Rich points were also used to ensure that the three source texts (English, French and German) for the direct translation task were really comparable. Test subjects answered a questionnaire for each text they translated, where they marked the global difficulty of the text on a scale of 30 points. Perception of difficulty was calculated on a scale between values 0 (easiest) and 1 (most difficult). Table 2 shows the results for the group of translators. No significant difference in text difficulty was perceived among the three STs. The comparability of the texts was thus validated by the subjects' perception of the global difficulty of the ST they were given to translate.

\begin{tabular}{|c|c|}
\hline $\begin{array}{c}\text { Translators' group } \\
\text { (translating from) }\end{array}$ & $\begin{array}{c}\text { ST global difficulty } \\
\text { perceived }\end{array}$ \\
\hline English ST & 0.27 \\
\hline French ST & 0.30 \\
\hline German ST & 0.30 \\
\hline
\end{tabular}

Table 2. Perception of ST global difficulty in direct translation. 
Table 3 displays results of the group of translators for the ST in inverse translation. All subjects were evaluating the same ST and they all perceived it to be "relatively difficult to translate." This result seems not only to validate the experimental texts but also the sample, for there was no important language-dependent difference in the perceived ST difficulty in both directions; the questionnaire used to select subjects for the experimental group of translators was therefore appropriate. This method could be used in other contexts where comparable or parallel texts are needed, for example, evaluating or predicting the difficulty of texts for teaching or testing.

\begin{tabular}{|c|c|}
\hline $\begin{array}{c}\text { Translators' group } \\
\text { (from Spanish ST into) }\end{array}$ & $\begin{array}{c}\text { ST global difficulty } \\
\text { perceived }\end{array}$ \\
\hline English & 0.63 \\
\hline French & 0.59 \\
\hline German & 0.59 \\
\hline
\end{tabular}

Table 3. Perception of ST global difficulty in inverse translation.

\section{Research into the Acquisition of Translation Competence}

We are still processing and analysing data from our ATC experiment, carried out in November 2011. As stated, results in this article focus on the 'knowledge-of-translation' variable.

\subsection{Definitions and theoretical model}

The TC general theoretical model and experimental design seems to have been validated by the TC experiment (see above and PACTE 2008, 2009, $2011 \mathrm{a}, 2011 \mathrm{~b})$. Given the productivity of the TC model, the sub-competences, variables and indicators used in the TC study was the basis for our ATC research. As represented in figure 1, the ATC is conceived as a spiral, a non-linear process integrating sub-competences and learning strategies.

This model, developed in 1998, includes insights from research into learning processes and postulates that ATC is a process of restructuring and developing sub-competences of TC. PACTE (2000) defined ATC as:

1. A dynamic, spiral process, that, like all learning processes, evolves from novice knowledge (pre-translation competence) to expert knowledge (translation competence); it requires learning competence 
(learning strategies). During the process, both declarative and procedural types of knowledge are integrated, developed, and restructured.

2. A process in which the development of procedural knowledge - and, consequently, of the strategic sub-competence-is essential.

3. A process in which the TC sub-competences are developed and restructured.

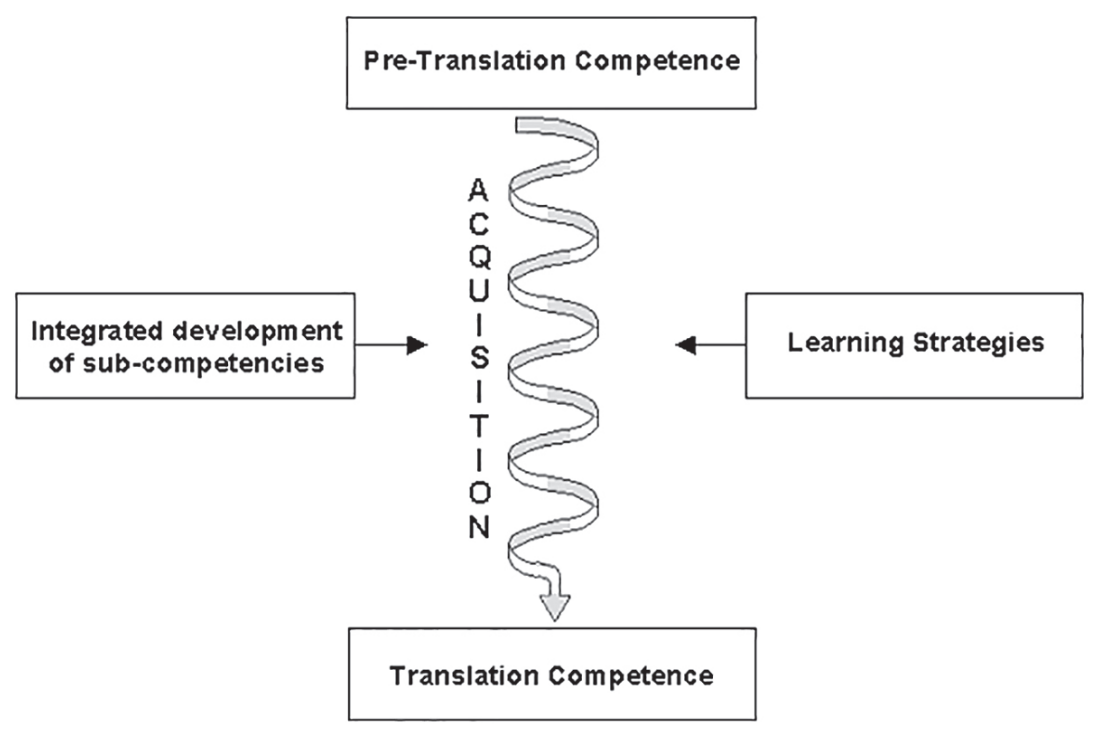

Figure 1. The ATC Model (PACTE 2000).

The process of acquiring sub-competences also involves relations, hierarchies and variations between them. In the ATC, the sub-competences: (1) are inter-related and compensate for each other; (2) do not always develop in parallel; (3) are organised hierarchically; (4) variations occur in relation to translation direction, language combinations, specialisation and the learning context. Therefore, the ATC process may not be parallel for direct and inverse translation. Furthermore, depending on the language combinations, the process may evolve at different speeds and, depending on the translation speciality (legal, literary translation, etc.), one sub-competence may be more important than another. The learning context (formal training, self-learning, etc.) has an influence on the acquisition process, as does the methodology used by teachers. 


\subsection{Acquisition of translation competence research design}

\subsubsection{General hypotheses}

The general hypothesis is that TC is acquired as a result of a process of development and restructuring of different sub-competences. Other hypotheses for the ATC study include:

1. TC comprises several inter-related sub-competences.

2. The development of the strategic, instrumental, and knowledge-of-translation sub-competences is particularly important.

3. Not all sub-competences develop in parallel, i.e., at the same time and at the same rate.

4. Learning-to-learn strategies must also be acquired.

5. The ATC is dependent upon directionality (direct/inverse translation), language pairs in use, the field of specialized translation (legal, literary translation, etc.) and the learning environment.

\subsubsection{Variables}

Table 4 (adapted from PACTE 2005a, 2005b) summarises definitions, indicators, data-collection instruments and data sources on the dependent variables selected for the TC and ATC experiments.

\begin{tabular}{|l|l|}
\hline \multicolumn{1}{|c|}{$\begin{array}{c}\text { KNOWLEDGE OF TRANSLATION } \\
\text { Related to the knowledge-of-translation sub-competence }\end{array}$} \\
\hline definition & The subject's implicit knowledge about the principles of translation \\
\hline indicators & $\begin{array}{l}\text { Dynamic index of knowledge of translation; Coherence coefficient of } \\
\text { knowledge of translation }\end{array}$ \\
\hline instruments & Knowledge-of-translation questionnaire \\
\hline \multicolumn{1}{c|}{$\quad \begin{array}{c}\text { TRANSLATION PROJECT } \\
\text { Related to the strategic sub-competence }\end{array}$} \\
\hline definition & $\begin{array}{l}\text { The subject's approach to the translation of a specific text and of the } \\
\text { units it comprises in a specific context }\end{array}$ \\
\hline indicators & $\begin{array}{l}\text { Dynamic index of the overall translation project; Dynamic index of the } \\
\text { translation project for translation problems; Coherence coefficient of } \\
\text { the translation project; Acceptability }\end{array}$ \\
\hline instruments & $\begin{array}{l}\text { Translations; Translation problems questionnaire; and Retrospective } \\
\text { interview }\end{array}$ \\
\hline
\end{tabular}




\begin{tabular}{|c|c|}
\hline \multicolumn{2}{|c|}{$\begin{array}{l}\text { IDENTIFICATION AND SOLUTION OF TRANSLATION PROBLEMS } \\
\text { Related to the strategic sub-competence and the knowledge-of-translation sub-competence }\end{array}$} \\
\hline definition & $\begin{array}{l}\text { Subjects' identification and solution of difficulties when carrying out a } \\
\text { translation task }\end{array}$ \\
\hline indicators & $\begin{array}{l}\text { Perception of the difficulty coefficient; Identification of prototypical } \\
\text { translation problems; Characterisation of prototypical translation } \\
\text { problems; Satisfaction coefficient; Acceptability }\end{array}$ \\
\hline instruments & $\begin{array}{l}\text { Translations; Translation problems questionnaire; and Retrospective } \\
\text { interview }\end{array}$ \\
\hline \multicolumn{2}{|r|}{$\begin{array}{c}\text { DECISION-MAKING } \\
\text { Related to strategic and instrumental sub-competences }\end{array}$} \\
\hline definition & $\begin{array}{l}\text { Decisions made during the translation process that involve the use } \\
\text { of automatized and non-automatized cognitive resources (internal } \\
\text { support) and the use of different sources of documentation (external } \\
\text { support) (Alves, 1995, 1997) }\end{array}$ \\
\hline indicators & Sequences of actions; Type of internal support; Acceptability \\
\hline instruments & Translations; Direct observation chart; PROXY; and Camtasia \\
\hline \multicolumn{2}{|r|}{$\begin{array}{l}\text { EFFICACY OF THE TRANSLATION PROCESS } \\
\text { Related to the strategic sub-competence }\end{array}$} \\
\hline definition & $\begin{array}{l}\text { Relationship between time taken to complete a translation task and the } \\
\text { acceptability of the solution }\end{array}$ \\
\hline indicators & $\begin{array}{l}\text { Total time taken; Time taken at each stage: orientation, development, } \\
\text { revision (based on Jakobsen 2002); Acceptability }\end{array}$ \\
\hline instruments & Translations; Direct observation chart; PROXY; and Camtasia \\
\hline \multicolumn{2}{|r|}{$\begin{array}{l}\text { USE OF INSTRUMENTAL RESOURCES } \\
\text { Related to the instrumental sub-competence }\end{array}$} \\
\hline definition & $\begin{array}{l}\text { Documentation strategies used when consulting resources in electronic } \\
\text { format (websites, dictionaries and encyclopaedias in CD-ROM) }\end{array}$ \\
\hline indicators & $\begin{array}{l}\text { Number of resources; Total time taken on searches; Time taken on } \\
\text { searches at each stage; Number of searches; Variety of searches; } \\
\text { Acceptability }\end{array}$ \\
\hline instruments & Translations; Camtasia \\
\hline
\end{tabular}

Table 4. Variables, indicators and instruments.

The dependent variables were the same as in the TC experiment, namely knowledge of translation; translation project; identification and solution of translation problems; decision-making; efficacy of the translation process; and use of instrumental resources. However, the independent variable in the $\mathrm{TC}$ experiment was defined as the degree of translation expertise, in terms of 
years of experience translating and the percentage of income from translation, whereas in the ATC experiment it was defined as years of translator training (first, second, third, fourth-year, and recently graduated students).

\subsubsection{A simulation of a longitudinal study}

The obvious choice to study the acquisition of a competence is a longitudinal study with several measurements at regular intervals. In our case, this option would have entailed taking repeated measurements from one sample of students over a period of five years and then to compare their results with those from the translators in the TC experiment. We would have followed one group of 30 students when they started the four-year degree at the UAB School of Translation and Interpreting, testing them before they started and then at regular yearly intervals. However, this kind of study has several practical and technical problems. The first problem relates to the time it would take to collect the data, because five years is a long time for a university research group. Second, comparable instruments would have to be developed and tested for each measurement. Creating five batteries of texts, questionnaires, and so on is no easy task. Third, difficulties would arise associated with the control of extraneous variables, such as external influences that might affect students' language and translation skills, or technological changes in hardware and software. The results of the TC experiment showed important differences between translators and teachers with regard to the instrumental sub-competence. Since the development and integration of this sub-competence is taken to be essential to ATC, technological changes, e.g., in documentation tools may affect this process. Fourth, attrition rates would probably be quite high, for maintaining the same group of subjects over five years is quite problematic.

Given all these problems, it was decided to carry out a simulation of a longitudinal study by taking simultaneous measurements from groups of first-year, second-year, third-year, and fourth-year students, as well as from a group of recent graduates, a total of 130 subjects (see figure 2). All the data was collected in November 2011, when first-year students had only been in the Faculty for a couple of weeks, so they could still be considered novices. The group of recent graduates had finished their degrees in June and they agreed to come back and do the experimental tasks in November, for a fee. The advantages of this strategy outweighed any disadvantages: all the data could be collected in one month, using the tasks and instruments validated in the TC experiment. 


\subsubsection{Universe and sample}

A pilot study in June 2011 comprised 15 fourth-year students. The experiment was carried out in November 2011 with 130 students from the five groups described above. The language combinations were the same as in the TC experiment. The experimental sample was screened with an initial questionnaire. A group of approximately 30 students for each year were selected from those students that passed the filter. Selected students had Spanish or Catalan as their A language; were within the average age group for their year; had not transferred from another degree course; had passed at least $80 \%$ of the previous year's subjects (including translation and A and B language subjects). The control group consisted of the 35 professional translators from the TC experiment

\subsubsection{Tasks and instruments}

The experimental tasks—also the same as in the TC experiment-were:

1. The knowledge-of-translation questionnaire.

2. Direct translation (B-A), followed by a questionnaire on the translation problems found.

3. Inverse translation (A-B), followed by a questionnaire on the translation problems found.

Most instruments had been validated in the TC experiment: the observation instrument (Camtasia); the initial questionnaire (revised); the translation problems questionnaire (revised); the knowledge-of-translation questionnaire; texts (rich points and criteria for acceptable, semi-acceptable and non acceptable solutions). All the questionnaires were filled in on-line.

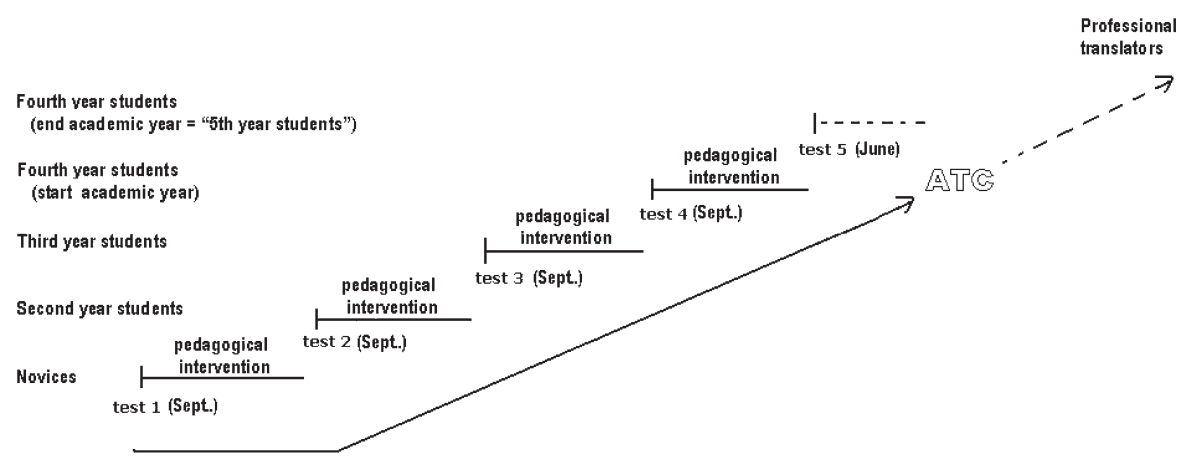

Figure 2. Simulation of a longitudinal study. 


\section{Declarative knowledge of translation: Translation Competence}

This variable provides data on the sub-competence 'knowledge of translation'. Defined in terms of the subject's implicit knowledge of the principles of translation, the indicators are the dynamic index and the coherence coefficient. The dynamic index of 'knowledge of translation' allows us to see whether a subject's implicit knowledge about translation is more "dynamic" (textual, interpretative, communicative and functional concept of translation), or more "static" (linguistic and literal concept of translation). The coherence coefficient of 'knowledge of translation' allows us to see if the subject's vision of different aspects of translation is consistently dynamic or static, and therefore whether the subject has a coherent concept of translation. The data is obtained from subjects' answers to the knowledge-of-translation questionnaire (see table 5).

\subsection{Instrument: Knowledge-of-translation questionnaire}

For the full questionnaire, results of this variable, and information on how the questionnaire was developed, see Neunzig and Kuznik (2007) and PACTE (2008, 2011a). The questionnaire is based on seven factors related to knowledge about translation: concept of translation and TC; translation units; translation problems; phases in the translation process; methods required; procedures used (strategies and techniques, etc.); role of the translation brief; and the role of the target reader. For each factor, statements were formulated based on two paradigms or ways of thinking about translation. One was labelled dynamic (D)—textual, interpretative, communicative, functionalist concepts - and the other one, static (S) - linguistic and literal concepts. The following two items from the questionnaire reflect these paradigms: (D) A text should be translated in different ways depending on who the target reader is (Item 10); (S) The aim of every translation is to produce a text as close in form to the original as possible (Item 4).

A questionnaire of 36 items was drawn up using test theory and item-theory criteria. The subjects' opinions were measured using Likert scaling in a forced choice method: I strongly disagree; I disagree; I agree; I strongly agree.

\begin{tabular}{|l|l|}
\hline \multicolumn{2}{|c|}{ KNOWLEDGE OF TRANSLATION } \\
Related to the knowledge-of-translation sub-competence
\end{tabular}




\begin{tabular}{|l|l|}
\hline \multirow{5}{*}{ hypotheses } & $\begin{array}{l}\text { EMPIRICAL } \\
\text { There is a relationship between the degree of translation competence and } \\
\text { knowledge of translation } \\
\text { OPERATIONAL } \\
\text { 1. Differences can be observed between translators and foreign language } \\
\text { teachers in relation to their concept of translation } \\
\text { 2. Differences can be observed between translators and foreign language } \\
\text { teachers in relation to the coherence of their concept of translation }\end{array}$ \\
\hline indicators & $\begin{array}{l}\text { 1. Dynamic index of Knowledge of Translation. } \\
\text { Numeric indicator; values: }-1 \text { to +1; data per subject: } 1 . \\
\text { 2. Coherence coefficient of Knowledge of Translation. } \\
\text { Numeric indicator; values: } 0 \text { to } 1 ; \text { data per subject: } 1 .\end{array}$ \\
\hline instruments & Knowledge-of-translation questionnaire \\
\hline data & Subjects' answers to the knowledge-of-translation questionnaire \\
\hline
\end{tabular}

Table 5. Knowledge-of-translation variable.

The questionnaire was later validated in the following stages. After trialling the questionnaire amongst lecturers and students in the UAB Schol of Translation and Interpreting (Stage 1), a pilot study (Stage 2) was carried out with three translators and three foreign language teachers who took part in the 2004 TC pilot study (PACTE 2005a, 2005b). The analysis of the data from this study suggested that neither the instrument nor the type of analysis were very effective at differentiating the two experimental groups.

\begin{tabular}{|c|c|c|}
\hline Pair & Dynamic item & Static item \\
\hline $\begin{array}{l}\text { 1st } \\
\text { brief and TT } \\
\text { audience }\end{array}$ & $\begin{array}{l}\text { Item } 3 \\
\text { The client conditions how the } \\
\text { translator translates a text. }\end{array}$ & $\begin{array}{l}\text { Item } 24 \\
\text { When you translate a text, you } \\
\text { should not be influenced by the target } \\
\text { reader. }\end{array}$ \\
\hline $\begin{array}{c}\text { 2nd } \\
\text { methods }\end{array}$ & $\begin{array}{l}\text { Item } 10 \\
\text { A text should be translated in } \\
\text { different ways depending on who } \\
\text { the target reader is. }\end{array}$ & $\begin{array}{l}\text { Item } 4 \\
\text { The aim of every translation is to } \\
\text { produce a text as close in form to the } \\
\text { original as possible. }\end{array}$ \\
\hline $\begin{array}{c}\text { 3rd } \\
\text { methods }\end{array}$ & $\begin{array}{l}\text { Item } 23 \\
\text { If you begin to translating a } \\
\text { text with certain criteria (e.g. } \\
\text { respecting the format of the original } \\
\text { text, adapting the text to the target } \\
\text { reader, etc.) these should be kept to } \\
\text { throughout the translation. }\end{array}$ & $\begin{array}{l}\text { Item } 11 \\
\text { All translated texts should keep } \\
\text { the same paragraphs and order of } \\
\text { sentences in the target text as in the } \\
\text { original text. }\end{array}$ \\
\hline
\end{tabular}




\begin{tabular}{|c|c|c|}
\hline $\begin{array}{c}\text { 4th } \\
\text { methods }\end{array}$ & $\begin{array}{l}\text { Item } 14 \\
\text { When translating a specialised } \\
\text { text, terminology is not the biggest } \\
\text { problem. }\end{array}$ & $\begin{array}{l}\text { Item } 5 \\
\text { Most translation problems can } \\
\text { be solved with the help of a good } \\
\text { dictionary. }\end{array}$ \\
\hline $\begin{array}{c}5 \text { th } \\
\text { methods }\end{array}$ & $\begin{array}{l}\text { Item } 27 \\
\text { If you find a word in a text you don't } \\
\text { understand, you should try to work } \\
\text { out its meaning from the context. }\end{array}$ & $\begin{array}{l}\text { Item } 16 \\
\text { As soon as you find a word you don't } \\
\text { know the meaning of, you should } \\
\text { look it up in a bilingual dictionary. }\end{array}$ \\
\hline
\end{tabular}

Table 6. Five pairs of selected opposing items.

A validation test (Stage 3) was designed to see if the questionnaire could really be used to measure our theoretical model in the experimental groups. The questionnaire was given to a sample of ten university science lecturers who were likely translation users. These subjects were chosen because they all knew foreign languages and were translation users but had no experience in translating or language teaching. The results confirmed that the tool did not collect data that distinguished the universe of foreign language professionals (translators and language teachers) from the universe of translation users (science lecturers).

Since the overall results of the questionnaire pilot study and the validation test did not clearly differentiate between the opinions expressed by the groups of subjects, the decision was taken to select five pairs of items that had differentiated the groups of subjects in earlier tests and that are conceptually clearly opposed. Table 6 displays the five pairs of items, which are mutually exclusive from a conceptual point of view and therefore give a clearer image of the subjects' opinions. In the TC experiment, our analysis is based on the answers given to these five pairs of items. ${ }^{6}$

Following scale-construction theory, items that did not provide relevant information in the pilot study were eliminated. The final version of the questionnaire (Stage 4) comprises 27 items, 12 of which indicate a dynamic concept of translation and 15 indicate a static concept (see appendix).

6. This approach has additional advantages: on the one hand, only 10 items are analysed (thereby saving time and effort). On the other, it is a more effective means of controlling 'missing' items since, when an item remains unanswered, its pair is automatically eliminated, thus ensuring the reliability of the data. 


\subsection{Results}

The subjects' answers were analysed for evidence of general tendencies among translators and teachers. Statistical analysis pointed to more dynamic tendencies among the translators and more static tendencies among the teachers (PACTE 2008, 2011a). These tendencies can be illustrated with the pair of items related to the 'methods required' provided as an example in section 4.1 above (item 10, dynamic; item 4, static). The translators had a much more dynamic concept of translation methods than the teachers. For the dynamic item, A text should be translated in different ways depending on who the target reader is, 13 translators and only 2 teachers chose 'I strongly agree', whereas the category 'I strongly disagree' was chosen by 7 teachers and only 1 translator. For the static item in the same pair, The aim of every translation is to produce a text as close in form to the original as possible, 8 teachers chose 'I strongly agree' and 11 more chose 'I agree', while 14 translators selected 'I disagree'.

\subsection{Dynamic index for translation competence}

The dynamic index allows us to see if a subject's implicit knowledge about how translation works is more dynamic or more static. In order to compute the dynamic index, numerical values $(-1$ to +1$)$ were attributed to the answers I strongly disagree; I disagree; I agree; I strongly agree. First the indicator was calculated for pairs of items for each subject and then for the experimental group. A comparison was made between the values of these indicators in the two experimental groups. Figure 3 shows the dynamic index of the subjects in the two groups.

TRANSLATORS

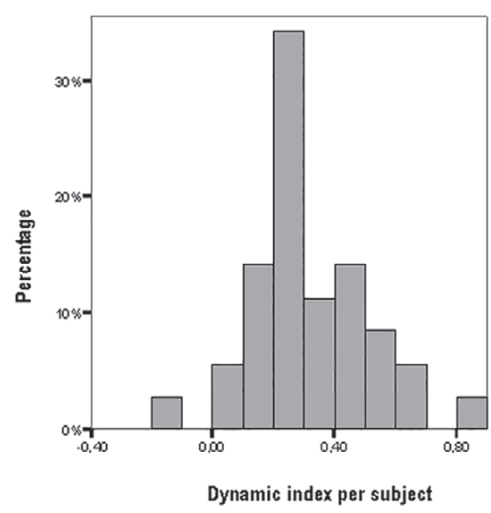

TEACHERS

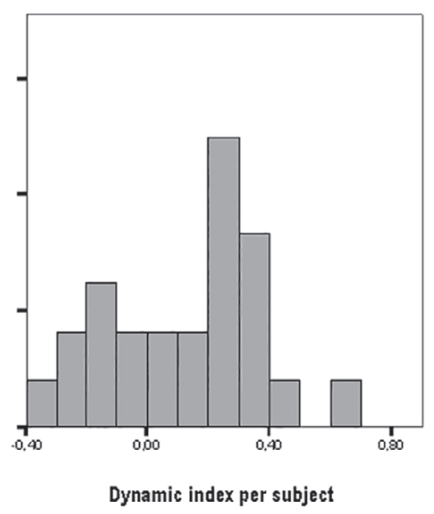

Figure 3. Dynamic Index of subjects in the two TC experimental groups. 
The mean dynamic index for translators is 0.273 and for teachers, 0.088 . The dynamic index of the translators' group is significantly higher than that of the teachers (p-value $<0.012$ ), at the significance level of $5 \%$, therefore it would seem that the translators as a group have a more dynamic concept of translation. Furthermore, if we look at the dynamic index of the first quartile of the sample in acceptability, the 9 'best' translators, the index rises from 0.27 to 0.36 . All the translators in this quartile have a high Acceptability Index between 1 and 0.9. They only have 'acceptable' or 'semi-acceptable' solutions and no 'non-acceptable solutions'. We could therefore conclude that a dynamic concept of translation is a characteristic of TC and affects translation quality.

\begin{tabular}{|l|c|}
\hline & Dynamic Index \\
\hline All translators & 0.27 \\
\hline Best translators & 0.36 \\
\hline Language teachers & 0.09 \\
\hline Translation users & -0.20 \\
\hline
\end{tabular}

Table 7. Dynamic Index.

\subsection{Coherence Coefficient for Translation Competence}

The coherence coefficient allows us to see if the subject's vision of the different functions is coherent or not. In order to compute the coherence coefficient, numerical values were attributed to three categories of coherence: 1, 'totally consistent' (the subject's concept of translation was totally static or totally dynamic); 0.5, 'partially consistent' (the subject's concept of translation was partially static or partially dynamic); and 0 , 'totally inconsistent'.

There is no relevant difference in the coherence coefficient between the language teachers $(0.27)$ and the translators $(0.37)$, both are positive, even though one may be more dynamic and the other more static. Therefore it could be assumed that both groups, as language professionals, have a coherent concept of what it means to mediate between two cultures, although the teachers tend towards a literal, linguistic concept of translation and the translators towards a more communicative and functional concept. However, if we compare the teachers with the 9 'best' translators, the differences are significant as the first quartile of translators have a coherence coefficient of 0.50 , i.e., they have a more coherent concept of translation. It is interesting to 
compare these results with those of the translation users (science teachers). Their mean coherence coefficient was only 0.05 , suggesting that they had no clear ideas about language or translation.

These results validate the criteria used in the TC experiment to select subjects and the sample. The two groups of language specialists held similarly coherent if different views on translation, the translation subjects tending to a dynamic concept and the language teachers to a static concept. These two groups were much more coherent than the translation users.

\begin{tabular}{|l|c|}
\hline Subjects & Coherence Coefficient \\
\hline All translators & 0.37 \\
\hline Best translators & 0.50 \\
\hline Language teachers & 0.27 \\
\hline Translation users & 0.05 \\
\hline
\end{tabular}

Table 8: Coherence Coefficient.

\section{Declarative knowledge of translation: Acquisition of Translation Competence}

In this section, we present the data for the dynamic index and the coherence coefficient in the ATC experiment, compare the results with those from the TC experiment, and indicate some further lines of inquiry that have emerged from this study.

\subsection{Dynamic index for the acquisition of translation competence}

The dynamic index results for the students are rather reassuring for translator trainers who take a functional, communicative stance. The students' concept of translation becomes increasingly dynamic through their training. On a

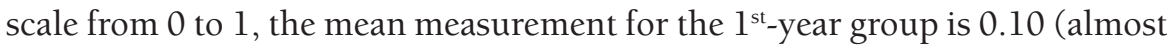
as static as the teachers in the TC test, with 0.09 ), while $4^{\text {th }}$-year students had a mean measurement of 0.36 (i.e., they were as dynamic as the best translators' in the TC experiment). Results for recent graduates were even higher, with 0.41 . 


\begin{tabular}{|l|r|c|l|c|c|}
\hline \multicolumn{4}{|c|}{ TC } & \multicolumn{3}{c|}{ ATC } \\
\hline subjects & $\mathrm{N}$ & Mean & \multicolumn{1}{|c|}{ students } & N & Mean \\
\hline Translators & 35 & 0.27 & $1^{\text {st }}$ Year & 24 & 0.10 \\
\hline Best translators & 9 & 0.36 & $2^{\text {nd }}$ Year & 26 & 0.33 \\
\hline Teachers & 24 & 0.09 & $3^{\text {rd }}$ Year & 26 & 0.37 \\
\hline Users & 10 & -0.20 & $4^{\text {th }}$ Year & 30 & 0.36 \\
\hline \multicolumn{3}{|r|}{} & Graduates & 22 & 0.41 \\
\hline
\end{tabular}

Table 9. Results for the dynamic index in TC and ATC experiments.

The difference between the beginning of the $1^{\text {st }}$ year and the beginning of the $2^{\text {nd }}$ year is noteworthy, with the index jumping from 0.10 to 0.33 . This dramatic change between the $1^{\text {st }}$ and the $2^{\text {nd }}$ year can also be seen in the coherence coefficient.

\subsection{Coherence coefficient for the acquisition of translation competence}

In the case of the coherence coefficient, the jump between $1^{\text {st }}$ year and $2^{\text {nd }}$ year students is even more remarkable-from 0.16 to 0.42 -but then the value remains more or less at the same level. It is as if after a year in the School of Translation, their views on language and translation had changed for goodor, at least, until the end of their degrees.

\begin{tabular}{|l|c|c|c|c|c|}
\hline \multicolumn{3}{|c|}{ TC } & \multicolumn{3}{c|}{ ATC } \\
\hline subjects & $\mathrm{N}$ & Mean & students & $\mathrm{N}$ & Mean \\
\hline Translators & 35 & 0.37 & $1^{\text {st }}$ Year & 24 & 0.16 \\
\hline Best translators & 9 & 0.50 & $2^{\text {nd }}$ Year & 26 & 0.42 \\
\hline Teachers & 24 & 0.27 & $3^{\text {rd }}$ Year & 26 & 0.42 \\
\hline Users & 10 & 0.05 & $4^{\text {th }}$ Year & 30 & 0.39 \\
\hline & & Graduates & 22 & 0.41 \\
\hline
\end{tabular}

Table 10. Results for the coherence coefficient in TC and ATC experiments.

\subsection{Further lines of inquiry and results}

As explained, five pairs of items were selected to calculate the dynamic and coherence indicators and so get 'a picture' of the subjects' views. In all of 
them there was a similarly abrupt change between the $1^{\text {st }}$-year 'novices' and more advanced students. We have also looked at the other statements in the Questionnaire to see what types of items showed a significant difference over the five years, so as to get a clearer picture about where the students' concept of translation changes. As the students are in the process of consolidating their ideas about translation, it was decided to convert the Likert scaling used to measure the subjects' opinion into a binary option. Thus, the answers "I strongly disagree," or "I disagree," are both interpreted as "Disagreement" and given 0 points and the answers "I agree" or "I strongly agree" are both interpreted as "Agreement" and count as 1 point. We are still analyzing this data and combining TC and ATC results. The following examples of items show a variety of trends and here offered to hint at possible future lines of inquiry.

\subsubsection{Items where nothing very interesting happens}

The responses to dynamic items 19 and 8-tables 11 and 12-do not seem to change over the ATC process, and novices and translators agree.

When you translate, you must bear in mind the text conventions of the target language.

\begin{tabular}{|l|c|c|c|c|c|c|}
\hline \multirow{2}{*}{ Item 19 } & \multicolumn{2}{|c|}{ Missing } & \multicolumn{2}{c|}{ Disagree } & \multicolumn{2}{c|}{ Agree } \\
\cline { 2 - 7 } & $\mathrm{N}$ & $\%$ Row & $\mathrm{N}$ & $\%$ Row & $\mathrm{N}$ & $\%$ Row \\
\hline $1^{\text {st }}$ Year & $\cdot$ & $\cdot$ & $\cdot$ & $\cdot$ & 24 & 100 \\
\hline $2^{\text {nd }}$ Year & 1 & 4 & $\cdot$ &. & 24 & 96 \\
\hline $3^{\text {rd }}$ Year & $\cdot$ & $\cdot$ & 3 & 10 & 25 & 89 \\
\hline $4^{\text {th }}$ Year & $\cdot$ & $\cdot$ & 1 & 3 & 29 & 96 \\
\hline Graduates & $\cdot$ & $\cdot$ & 4 & 18 & 18 & 81 \\
\hline Translators & 1 & 2 &. &. & 34 & 97 \\
\hline
\end{tabular}

Table 11. Item 19 (dynamic). 
If the characteristics of the source text are very different from those of the target culture (e.g., business letters, instruction manuals, etc.) you should adapt the target text accordingly.

\begin{tabular}{|l|c|c|c|c|c|c|}
\hline \multirow{2}{*}{ Item 8 } & \multicolumn{2}{|c|}{ Missing } & \multicolumn{2}{c|}{ Disagree } & \multicolumn{2}{c|}{ Agree } \\
\cline { 2 - 7 } & $\mathrm{N}$ & $\%$ Row & $\mathrm{N}$ & $\%$ Row & $\mathrm{N}$ & $\%$ Row \\
\hline $1^{\text {st }}$ Year & $\cdot$ & $\cdot$ & 2 & 8 & 22 & 91 \\
\hline $2^{\text {nd }}$ Year & $\cdot$ & $\cdot$ & 1 & 4 & 24 & 96 \\
\hline $3^{\text {rd }}$ Year & $\cdot$ & $\cdot$ & 2 & 7 & 26 & 92 \\
\hline $4^{\text {th }}$ Year & $\cdot$ & $\cdot$ & 5 & 16 & 25 & 83 \\
\hline Graduates & $\cdot$ &. &. &. & 22 & 100 \\
\hline Translators &. & $\cdot$ & 1 & 2 & 34 & 97 \\
\hline
\end{tabular}

Table 12. Item 8 (dynamic).

\subsubsection{Items hinting at growing dynamism}

The responses to items 12 (static) and 19 (dynamic)—tables 13 and 14-point to an increasingly dynamic translation concept, with significant increases between the first and the second years.

Idiomatic expressions are the biggest problem in translation.

\begin{tabular}{|l|c|c|c|c|c|c|}
\hline \multirow{2}{*}{ Item 12 } & \multicolumn{2}{|c|}{ Missing } & \multicolumn{2}{c|}{ Disagree } & \multicolumn{2}{c|}{ Agree } \\
\cline { 2 - 7 } & $\mathrm{N}$ & $\%$ Row & $\mathrm{N}$ & $\%$ Row & $\mathrm{N}$ & $\%$ Row \\
\hline $1^{\text {st }}$ Year & $\cdot$ & $\cdot$ & $\cdot$ &. & 24 & 100 \\
\hline $2^{\text {nd }}$ Year & $\cdot$ & $\cdot$ & 5 & 20 & 20 & 80 \\
\hline $3^{\text {rd }}$ Year & $\cdot$ &. & 4 & 14 & 24 & 85 \\
\hline $4^{\text {th }}$ Year & $\cdot$ & $\cdot$ & 11 & 36 & 19 & 63 \\
\hline Graduates & 1 & 4 & 6 & 27 & 15 & 68 \\
\hline Translators & $\cdot$ &. & 20 & 57 & 15 & 42 \\
\hline
\end{tabular}

Table 13. Item 12 (static). 
A text should be translated in different ways depending on who the target reader is.

\begin{tabular}{|l|l|l|c|c|c|c|}
\hline \multirow{2}{*}{ Item 10} & \multicolumn{2}{|c|}{ Missing } & \multicolumn{2}{c|}{ Disagree } & \multicolumn{2}{c|}{ Agree } \\
\cline { 2 - 7 } & $\mathrm{N}$ & $\%$ Row & $\mathrm{N}$ & $\%$ Row & $\mathrm{N}$ & $\%$ Row \\
\hline $1^{\text {st }}$ Year & $\cdot$ &. & 9 & 37 & 15 & 62 \\
\hline $2^{\text {nd }}$ Year & $\cdot$ &. & 1 & 4 & 24 & 96 \\
\hline $3^{\text {rd }}$ Year &. &. & 2 & 7 & 26 & 92 \\
\hline $4^{\text {th }}$ Year &. &. & 5 & 16 & 25 & 83 \\
\hline Graduates &. &. & 4 & 18 & 18 & 81 \\
\hline Translators &. &. & 7 & 20 & 28 & 80 \\
\hline
\end{tabular}

Table 14. Item 10 (dynamic).

\subsubsection{Items reflecting formal training and professional experience}

The responses to items 9 and 16, related to the use of bilingual dictionaries (tables 15 and 16), show a sharp increase in dynamism between the first and second year that is maintained up until the end of the degree course. However, the translators (and the graduates, in item 16) show decreased dynamism. This might simply be due to trainers teaching their students not to trust bilingual dictionaries, whereas professional experience has taught translators to trust their internal support strategies and to use them well when consulting a bilingual dictionary, without accepting automatically the first solution they find.

Since you can't be expected to know all the words, a good bilingual dictionary is the best way to ensure a good translation.

\begin{tabular}{|l|c|c|c|c|c|c|}
\hline \multirow{2}{*}{ Item 9 } & \multicolumn{2}{|c|}{ Missing } & \multicolumn{2}{c|}{ Disagree } & \multicolumn{2}{c|}{ Agree } \\
\cline { 2 - 7 } & $\mathrm{N}$ & $\%$ Row & $\mathrm{N}$ & $\%$ Row & $\mathrm{N}$ & $\%$ Row \\
\hline $1^{\text {st }}$ Year & $\cdot$ &. & 1 & 4 & 23 & 95 \\
\hline $2^{\text {nd }}$ Year & $\cdot$ &. & 9 & 36 & 16 & 64 \\
\hline $3^{\text {rd }}$ Year & $\cdot$ &. & 14 & 50 & 14 & 50 \\
\hline $4^{\text {th }}$ Year & $\cdot$ & $\cdot$ & 20 & 66 & 10 & 33 \\
\hline Graduates & 1 & 4 & 19 & 86 & 2 & 9 \\
\hline Translators &. &. & 18 & 51 & 17 & 48 \\
\hline
\end{tabular}

Table 15. Item 9 (static). 
As soon as you find a word you don't know the meaning of, you should look it up in a bilingual dictionary.

\begin{tabular}{|l|c|c|c|c|c|c|}
\hline \multirow{2}{*}{ Item 16 } & \multicolumn{2}{|c|}{ Missing } & \multicolumn{2}{c|}{ Disagree } & \multicolumn{2}{c|}{ Agree } \\
\cline { 2 - 7 } & $\mathrm{N}$ & $\%$ Row & $\mathrm{N}$ & $\%$ Row & $\mathrm{N}$ & $\%$ Row \\
\hline $1^{\text {st }}$ Year & $\cdot$ &. & 7 & 29 & 17 & 70 \\
\hline $2^{\text {nd }}$ Year & 1 & 4 & 17 & 68 & 7 & 28 \\
\hline $3^{\text {rd }}$ Year & $\cdot$ &. & 23 & 82 & 5 & 17 \\
\hline $4^{\text {th }}$ Year & 1 & 3 & 24 & 80 & 5 & 16 \\
\hline Graduates &. &. & 15 & 68 & 7 & 31 \\
\hline Translators & $\cdot$ &. & 19 & 54 & 16 & 45 \\
\hline
\end{tabular}

Table 16. Item 16 (static).

This brief look at some of the 27 items in the knowledge-of-translation questionnaire has lead us to think that it may be worth looking further into the seven factors we took as our starting point when designing the questionnaire: concept of translation and TC, translation units, translation problems, phases in the translation process, methods required, procedures used (strategies and techniques, etc.), role of the translation brief, and the role of the target reader.

\section{Conclusions}

This article has presented the results related to the knowledge-of-translation variable in PACTE's ATC experiment. These results have been compared with those in the TC experiment. The TC results showed that TC implies a dynamic concept of translation. They also revealed a relationship between the knowledge-of-translation variable (declarative knowledge) and another variable, that of the translation project (procedural knowledge). These results showed a close relationship between a dynamic concept of translation (dynamic index of knowledge of translation), a dynamic translation project for a specific text (dynamic index of the overall translation project), and a dynamic project for the translation problems posed in the text (dynamic index of the translation project for translation problems). We labelled the relationship between the three indicators the dynamic translation index. We also established a correlation between this index and the acceptability of the solutions to these problems (PACTE $2011 \mathrm{a}$, in progress). The more dynamic the index is, the more acceptable the translations are. 
We have come to the conclusion that these findings corroborate the theoretical models proposed by those pioneers who, in the second half of the 20th century challenged the linguistic models that were dominant in Translation Studies and introduced communicative and functionalist paradigms. These models include Nida's (1964) dynamic equivalence; Seleskovitch's (1968) and Seleskovitch \& Lederer's (1984) equivalence of meaning; Reiss \& Vermeer's (1984) and Nord's (1991) functional equivalence; Hatim \& Mason's (1990) communicative translation, etc. This communicative, functionalist paradigm continues to provide a useful framework for translation practice and research in the 21 st century.

The ATC results analysed thus far seem to confirm the importance of a dynamic concept of translation in TC. They show that the progression from a static to a dynamic declarative knowledge of translation is a characteristic of the ATC. The students' dynamic index of knowledge of translation develops consistently throughout the translation program, from 0.10 in $1^{\text {st-year stu- }}$ dents to 0.41 in recent graduates. After initial training, all students, including the $2^{\text {nd }}$-year students, have more dynamic results than the group of professional translators in the TC experiment. The recent graduates are even more dynamic than the 9 "best" translators (the experts).

Of particular interest is the important leap between the $1^{\text {st }}$ and $2^{\text {nd }}$-year students' (from 0.10 to 0.33 ). At UAB, $2^{\text {nd }}$-year students have only had one semester of practical translation courses but none in translation theory, so it would seem that they develop implicit theories about the dynamic nature of translation from their own experience in translation. These implicit theories are reinforced throughout their training and seem to become ingrained.

To learn more about this progression from static to dynamic notion in the ATC, we plan to take the following steps:

1. Analyze the data from the translation project variable. This includes the approach to the translation of a specific text (dynamic index of the overall translation project) and the approach to units of the text (dynamic index of the translation project for translation problems).

2. Cross this data with the dynamic index of knowledge of translation to obtain the dynamic translation index in the ATC.

3. Analyze the data of the transversal acceptability indicator, the quality of the translations.

4. Cross the data of the acceptability indicator with the dynamic translation index. 
Once we have analysed this data, we will have a better idea of when students are able to convert this dynamic declarative knowledge of translation into an overall dynamic approach to the translation of a specific text and to finding acceptable solutions to translation problems in a text within a given context. How and when translator trainees acquire a dynamic concept and approach to translation (declarative and procedural knowledge) is an important aspect of the ATC study. We believe it is a key element in the move from 'novice' knowledge (pre-translation competence) to translation competence.

\section{References}

AlVES, Fábio. (1995) Zwischen Schweigen und Sprechen: Wie bildet sich eine transkulturelle Brücke? Eine Analyse von Übersetzungsvorgängen zwischen portugiesischen und brasilianischen Übersetzern. Hamburg: Dr. Kovac.

Alves, Fábio. (1997) "A formação de tradutores a partir de uma abordagem cognitiva: Reflexões de um projeto de ensino." TradTerm 4:2, pp. 19-40.

GIEGLER, Helmut. (1994) "Test und Testtheorie." In: Asanger, Roland \& Gerd Wenninger (eds.) 1994. Wörterbuch der Psychologie. Weinheim: Beltz Psychologie Verlags Union, pp. 782-789.

Hatim, Basil \& Ian Mason. (1990) Discourse and the Translator. London: Longman.

JAKOBSEN, Arnt L. (2002) "Orientation, segmentation, and revision in translation. In: Hansen, Gyde (ed.) 2002. Empirical Translation Studies: Process and Product. Copenhagen: Samfundslitteratur, pp. 191-204.

KRINGS, Hans P. (1986) Was in den Köpfen von Übersetzern vorgeht. Eine empirische Untersuchung zur Struktur des Übersetzungsprozesses an fortgeschrittenen Französischlernern. Tübingen: Narr.

NEUNZIG, Wilhelm. (2011) "Empirical studies in translation: Methodological and epistemological questions, Traduction, Terminologie, Rédaction 24:2, pp. $15-40$.

NeUNZIG, Wilhelm \& Anna Kuznik. (2007) "Probleme der übersetzungswissenschaftlichen Forschung: zur Entwicklung eines Einstellungsfragebogens." In: Schmitt, Peter A. \& Heike E.Jüngst (eds.) 2007. Translationsqualität. Frankfurt: Peter Lang, pp. 445-456.

NIDA, Eugene. (1964) Toward a Science of Translating, with special reference to principles and procedures involved in Bible translating. Leiden: E. J. Brill.

NorD, Christiane. (1991) Text Analysis in Translation. Amsterdam: Rodopi.

PACTE. (2000) "Acquiring Translation Competence: Hypotheses and methodological problems in a research project." In: Beeby, Allison; Doris 
Ensinger \& Marisa Presas (eds.) 2000. Investigating Translation. Amsterdam: John Benjamins, pp. 99-106.

PACTE. (2002) "Exploratory tests in a study of translation competence." Conference Interpretation and Translation 4:2, pp. 41-69.

PACTE. (2003) "Building a Translation Competence model." In: Alves, Fábio (ed.) 2003. Triangulating Translation. Amsterdam: John Benjamins, pp. 43-66.

PACTE. (2005a) "Primeros resultados de un experimento sobre la Competencia Traductora." Actas del II Congreso Internacional de la Asociación Ibérica de Estudios de Traducción e Interpretación. Madrid: Universidad Pontificia Comillas, pp. 573-587 (CD-ROM).

PACTE. (2005b) "Investigating Translation Competence: Conceptual and methodological issues." Meta 50:2, pp. 609-619.

PACTE. (2008) "First results of a Translation Competence experiment: 'Knowledge of translation' and 'efficacy of the translation process'." In: Kearns, John (ed.) 2008. Translator and Interpreter Training. Issues, Methods and Debates. London: Continuum, pp. 104-126.

PACTE. (2009) "Results of the validation of the PACTE Translation Competence model: Acceptability and decision-making." Across Languages and Cultures 10:2, pp. 207-230.

PACTE. (2011a) "Results of the validation of the PACTE Translation Competence model: Translation project and dynamic translation index." In: O'Brien, Sharon (ed.) 2011. Cognitive Explorations of Translation. London: Continuum, pp. 30-56.

PACTE. (2011b) "Results of the validation of the PACTE Translation Competence model: Translation problems and Translation Competence." In: Tiselius, Elisabet; Cecilia Alvstad \& Adelina Hild (eds.) 2011. Methods and Strategies of Process Research: Integrative Approaches in Translation Studies. Amsterdam: John Benjamins, pp. 317-343.

PACTE. [in progress] Researching Translation Competence.

REISS, Katharina \& Hans Vermeer. (1984) Grundlegung einer Allgemeinen Translationstheorie. Tübingen: Niemeyer [1996. Fundamentos para una Teoría Funcional de la Traducción. Trad. de Sandra Reina García \& Celia Martín de León. Madrid: Akal].

SELESKOVITCH, Danica. (1968) Linterprète dans les conférences internationales. Problèmes de langage et de communication. Paris: Minard.

SeleskovitCH, Danica \& Marianne Lederer. (1984) Interpréter pour traduire. Paris: Didier Érudition. 


\section{Appendix}

\section{Knowledge-of-translation questionnaire ${ }^{7}$}

\section{What is your opinion about the following statements?}

1. As you read the source text, you are already thinking about how you are going to translate it.

$\square$ I strongly disagree $\square$ I disagree $\square$ I agree $\square$ I strongly agree

2. You always lose something in translation since words do not normally mean exactly the same in the source language as in the target language.

$\square$ I strongly disagree $\square$ I disagree $\square$ I agree $\square$ I strongly agree

3. The client conditions how the translator translates a text.

$\square$ I strongly disagree $\square$ I disagree $\square$ I agree $\square$ I strongly agree

4. The aim of every translation is to produce a text as close in form to the original as possible.

$\square$ I strongly disagree $\square$ I disagree $\square$ I agree $\square$ I strongly agree

5. Most translation problems can be solved with the help of a good dictionary.

$\square$ I strongly disagree $\square$ I disagree $\square$ I agree $\square$ I strongly agree

6. When you translate a text you must satisfy target reader expectations.

$\square$ I strongly disagree $\square$ I disagree $\square$ I agree $\square$ I strongly agree

7. In order to understand the source text, the most important thing to do is to solve vocabulary problems.

$\square$ I strongly disagree $\square$ I disagree $\square$ I agree $\square$ I strongly agree

8. If the characteristics of the source text are very different from those of the target culture (e.g. business letters, instruction manuals, etc.) you should adapt the target text accordingly.

$\square$ I strongly disagree $\square$ I disagree $\square$ I agree $\square$ I strongly agree

9. Since you can't be expected to know all the words, a good bilingual dictionary is the best way to ensure a good translation.

$\square$ I strongly disagree $\square$ I disagree $\square$ I agree $\square$ I strongly agree

7. The original questionnaire is in Spanish. 'Dynamic' questions are \# 1, 3, 6, 8, 10, 14, 17 , 19, 20, 21, 23 and 27; 'Static' questions are \# 2, 4, 5, 7, 9, 11, 12, 13, 15, 16, 18, 22, 24, 25 and 26. 
10. A text should be translated in different ways depending on who the target reader is.

$\square$ I strongly disagree $\square$ I disagree $\square$ I agree $\square$ I strongly agree

11. All translated texts should keep the same paragraphs and order of sentences in the target text as in the original text.

$\square$ I strongly disagree $\square$ I disagree $\square$ I agree $\square$ I strongly agree

12. Idiomatic expressions are the biggest problem in translation.

$\square$ I strongly disagree $\square$ I disagree $\square$ I agree $\square$ I strongly agree

13. The best way to translate is to concentrate on the words and syntax of the original and then reproduce them in the target language.

$\square$ I strongly disagree $\square$ I disagree $\square$ I agree $\square$ I strongly agree

14. When translating a specialized text, terminology is not the biggest problem.

$\square$ I strongly disagree $\square$ I disagree $\square$ I agree $\square$ I strongly agree

15. With the exception of proverbs, idioms, and metaphors, the best way to translate is always word for word.

$\square$ I strongly disagree $\square$ I disagree $\square$ I agree $\square$ I strongly agree

16. As soon as you find a word you don't know the meaning of, you should look it up in a bilingual dictionary.

$\square$ I strongly disagree $\square$ I disagree $\square$ I agree $\square$ I strongly agree

17. One of the biggest problems when translating a novel is cultural references (e.g. institutions; typical dishes, etc.).

$\square$ I strongly disagree $\square$ I disagree $\square$ I agree $\square$ I strongly agree

18. When you translate, you concentrate on one sentence and translate it, then the next, and so on until you have translated the whole text.

$\square$ I strongly disagree $\square$ I disagree $\square$ I agree $\square$ I strongly agree

19. When you translate, you must bear in mind the text conventions of the target language.

$\square$ I strongly disagree $\square$ I disagree $\square$ I agree $\square$ I strongly agree

20. It is not enough to know two languages well to be able to translate well.

$\square$ I strongly disagree $\square$ I disagree $\square$ I agree $\square$ I strongly agree 
21. When you translate an essay you must ensure that target readers react to the text in the same way as the source text readers.

$\square$ I strongly disagree $\square$ I disagree $\square$ I agree $\square$ I strongly agree

22. When you find a cultural reference in a text (e.g. a typical dish) you should try to find a similar reference in the target culture.

$\square$ I strongly disagree $\square$ I disagree $\square$ I agree $\square$ I strongly agree

23. If you begin translating a text with certain criteria (e.g. respecting the format of the original text, adapting the text to the target reader, etc.) these should be kept to throughout the translation.

$\square$ I strongly disagree $\square$ I disagree $\square$ I agree $\square$ I strongly agree

24. When you translate a text, you should not be influenced by the target reader.

$\square$ I strongly disagree $\square$ I disagree $\square$ I agree $\square$ I strongly agree

25. The best way to translate a text is to translate sentence by sentence.

$\square$ I strongly disagree $\square$ I disagree $\square$ I agree $\square$ I strongly agree

26. The same translation problems come up in every text.

$\square$ I strongly disagree $\square$ I disagree $\square$ I agree $\square$ I strongly agree

27. If you find a word in a text you don't understand, you should try to work out its meaning from the context.

$\square$ I strongly disagree $\square$ I disagree $\square$ I agree $\square$ I strongly agree

\section{BIONOTE / NOTA BIOGRÁFICA}

PACTE has been a competitive research group since 1997. PACTE's main research interests are empirical and experiment-based research on translation competence and its acquisition in written translation; translator training; empirical and experimental research in Translation Studies; and the use of new technologies in translation research. The group was awarded the Universitat Autònoma de Barcelona Prize for Outstanding Research (PREI2010 UAB) for the article "Results of the validation of the PACTE translation Competence Model: Acceptability and decision-making," published in 2009 in Across Languages and Cultures 10:2.

PACTE es un grupo de investigación competitivo desde 1997. Los intereses investigadores fundamentales del grupo son la investigación 
empírico experimental sobre la competencia traductora y su adquisición en la traducción escrita; la formación de traductores; la metodología empírica y experimental en Traductología, y el uso de las TIC en la investigación de la traducción. El grupo ha sido galardonado con el Premio a la Excelencia investigadora (PREI2010 UAB) otorgado por la Universidad Autònoma de Barcelona (Área de Humanidades) por el artículo "Results of the validation of the PACTE translation Competence Model: Acceptability and decisionmaking," publicado en 2009 en Across Languages and Cultures 10:2. 